\title{
Varicocele e infertilidad masculina
}

\author{
Alberto Arévalo M.D.; F.A.C.S.; F.I.C.S.; Alfonso Baquero M.D.; \\ José Osorio M.D. y Hernando Varela M.D.
}

El varicocele como causa de infertilidad masculina ha sido un tema controvertido. Aunque no todos producen infertilidad, se les ha asociado según los autores en un amplio márgen del $4 \%$ al $39 \%(1)$. Varias teorías se han invocado como causales de infertilidad tales como aumento de la temperatura local, reflujo y alteraciones hormonales especialmente en el varicocele bilateral (2).

\section{MATERIAL Y METODOS}

Se revisaron 251 historias clínicas de la Unidad de Fertilidad Humana de la Clínica San Pedro Claver y se encontraron 48 pacientes con varicocele izquierdo solo o asociado a otros trastornos productores potenciales de infertilidad, siguiendo los siguientes parámetros:

1. Historia clínica estandarizada.

2. Exámenes generales de laboratorio que incluian cuadro hemático, tiempo de protrombina, glicemia, serología, hemoclasificación, parcial de orina $y$ dos espermogramas como mínimo. En caso de pio-esperma, cultivo $y$ antibiograma de líquido prostático $y$ de semen, con controles bacteriolóqi-

Unidad de Fertilidad Humana. Clínica San Pedro Claver. Instituto de Seguridad Social. Bogotá. Sociedad Colombiana de Urología. Sociedad Colombiana de Andrología. cos post-tratamiento médico. Por lo menos dos espermogramas post-operatorios en el lapso de un año. Dosificaciones hormonales hipofisiarias, testosterona y estudio genético en pacientes azoospérmicos.

3. Con igual técnica quirúrgica se practicaron 20 varicocelectomias sola y 9 asociadas a biopsia testicular bilateral en pacientes azoospérmicos.

4. Los parámetros de estudio en los espermogramas fueron: recuento, movilidad inicial rápida y morfología.

5. Se analizó el factor femenino como causal de infertilidad conyugal.

6. Seguimiento post-operatorio de las varicocelectomías con espermogramas, por lo menos de seis meses.

7. Se analizaron los embarazos obtenidos mediante tratamiento.

8. EI presente trabajo contempla las especiales condiciones socio económicas que existen en el país, en el hombre infertil.

\section{RESULTADOS}

Edad: mínima 23 años. Máxima 40. Promedio 30 años.

Tiempo de infertilidad conyugal previa; según histórica cl ínica: 
Mínimo 1 año. Máximo 9 años. Promedio 3.5 años.

\begin{tabular}{|c|c|c|c|}
\hline \multicolumn{4}{|c|}{$\begin{array}{l}\text { Factores asociados; (Ambientales, } \\
\text { ocupacionales y sexológicos): }\end{array}$} \\
\hline Hipertermia & \multicolumn{2}{|c|}{ (pacientes) } & 1 \\
\hline \multicolumn{3}{|l|}{ Trabajo bajo calor } & 4 \\
\hline \multicolumn{3}{|c|}{$\begin{array}{l}\text { Contacto con químicos } \\
\text { Sexológicos (eyaculación precoz) }\end{array}$} & $\begin{array}{l}1 \\
2\end{array}$ \\
\hline \multicolumn{3}{|c|}{ Total } & 8.31 \\
\hline \multicolumn{4}{|c|}{ Factor inflamatorio: 18 pacientes. 698} \\
\hline \multicolumn{3}{|c|}{ Prostatitis a Estaphilococo Albus } & 10 \\
\hline \multicolumn{3}{|l|}{ Idem. E. Coli } & 1 \\
\hline \multicolumn{3}{|c|}{ Idem. Trichomonas y Proteus } & 1 \\
\hline \multicolumn{3}{|l|}{ Prostatitis a Gonococo } & 1 \\
\hline \multicolumn{3}{|l|}{ Idem. a otros gérmenes } & 5 \\
\hline \multicolumn{3}{|c|}{ Total } & 18 \\
\hline \multicolumn{3}{|c|}{ Varicocelectomías (de 48 pacientes) } & 20 \\
\hline \multicolumn{3}{|c|}{$\begin{array}{l}\text { Varicocelectom ias y biopsias testicular } \\
\text { bilat. }\end{array}$} & 9 \\
\hline \multicolumn{3}{|l|}{ No operados } & 19 \\
\hline \multicolumn{4}{|c|}{ Espermogramas en admisión: } \\
\hline \multicolumn{3}{|l|}{ Normozoospérmicos } & 9 \\
\hline \multicolumn{3}{|l|}{ Anormales } & 30 \\
\hline \multicolumn{3}{|l|}{ Azoospérmicos } & 9 \\
\hline \multicolumn{4}{|c|}{$\begin{array}{l}\text { En estos } 30 \text { espermogramas se encon- } \\
\text { traron en promedio: }\end{array}$} \\
\hline \multicolumn{3}{|l|}{ Recuento } & 39 \\
\hline \multicolumn{3}{|l|}{ Mòvilidad rápida inicial } & 39 \\
\hline \multicolumn{3}{|c|}{ Morfología. Formas normales } & 69 \\
\hline \multicolumn{4}{|c|}{ Espermogramas post-operatorios: } \\
\hline \multicolumn{3}{|l|}{ Recuento promedio } & 45 \\
\hline \multicolumn{3}{|l|}{ Movilidad } & 49 \\
\hline \multicolumn{3}{|l|}{ Morfología } & 738 \\
\hline \multicolumn{4}{|c|}{ Cuadro comparativo de espermogramas; } \\
\hline \multicolumn{2}{|r|}{ Pre-op. } & \multicolumn{2}{|c|}{ Post-op. } \\
\hline Recuento & $39 \mathrm{M} . \mathrm{m} / \mathrm{l}$ & 45 & M. $\mathrm{m} / \mathrm{l}$ \\
\hline Movilidad & $39 \%$ & 49 & \\
\hline Morfología & 698 & 73 & \\
\hline
\end{tabular}

Biopsias testiculares bilaterales:

Normal (Obstructiva) '(Epidídimo-deferentostomfa) 1

Atrófia testicular bilateral (Azoospérmicos) 6

Testículo izquierdo normal. Derecho: atrofia testic. 1

Detención espermatogénesis en espermatide

Factor ginecológico asociado:

( 3 esposos normozoospérmicos)

Factor tubo-peritoneal

Sindrome anovulatorio

Embarazos:

Por inseminación artificial por donante (Azoospérmico)) 1

Embarazo y muerte por sufrimiento fetal

Idem. Muerte por circular del cordon

1

Normales en curso
En 251 pacientes infértiles se encontraron 48 pacientes con varicocele solo o asociado a otras causales de infertilidad. $19 \%$. De los 48 pacientes con varicocele se encontraron con solo varicocele $22(46 \%)$ y con varicocele y otros factores asociados 26 pacientes ( $54 \%$ ).

\section{CONCLUSIONES:}

1. El porcentaje de varicocele como causante de infertilidad masculina encontrado entre nosotros en los pacientes del Seguro Social, es aparentemente más bajo que el señalado por otros autores (1), pero está de acuerdo con estudios similares hechos en Colombia (2) (3) (4).

2. El factor inflamatorio registra una mayor incidencia en nuestro medio, quizás por la frecuencia de enfermedades venereas $y$ promiscuidad sexual (4).

3. El tratamiento concomitante del factor inflamatorio puede haber modificado los resultados finales, pero su evaluación separada sería muy difícil.

4. Los parámetros más afectados en el espermograma fueron el recuento y la movilidad.

5. No hallamos trastornos manifiestos en la morfología ni en el porcentaje de formas anormales, especialmente de formas ahuzadas (tapering).

6. Hay mejoría en el estudio comparativo de espermogramas pre $y$ postoperatorios, especialmente en el recuento y la movilidad.

7. El porcentaje de embarazos obtenidos en pacientes con oligoastenozoospermias (seis en total), de los 20 pacientes varicocelectomizados, es de un $30 \%$ que es alentador. 


\section{RESUMEN}

El propósito de este estudio fue evaluar el varicocele como una causa de infertilidad masculina, basado en historias clínicas, espermogramas, varicocelectomias, biopsias testiculares bilaterales y seguimiento post-operatorio. En 251 historias clínicas de infertilidad masculina, se encontraron 48 casos de varicocele izquierdo (19\%). Se practicaron 29 varicocelectomias, de las cuales 9 con biopsia testicular bilateral en pacientes azoospérmicos. Espermogramas

\section{BIBLIOGRAFIA}

1. DUBIN, L., and AMELAR R.D. (1971): Etiologic factor in 1924 cases of male infertility. Fertil Steril. 22; 469-474.

2. RODRIGUEZ. RIGAUD y col. (1978): a possible mechanisn for detrimental effect of varicocele on testicular function in man. Fertil. Steril. 30: 577-585. pre $y$ post operatorios se practicaron, con análisis de los embarazos obtenidos mediante tratamiento quirúrgico.

Factores asociados tales como: ambientales, ocupaciones, sexológicos $y$ ginecológicos se contemplaron en el estudio.

El varicocele es una causa de infertilidad masculina, frecuentemente asociada a factor inflamatorio. Observamos mejoría definida en espermogramas postoperatorios que condujeron a embarazos.

3. AREVAlo A., Estudio sobre 50 casos de infertilidad conyugal. Tribuna Médica Colombiana. 60: 21-25 julio 1979.

4. AREVAlO A., Estudio sobre 100 Historias Clínicas de Infertilidad conyugal. Unidad de Fertilidad Humana. Clínica San Pedro Claver. I.S.S. Revista Colombiana de Ginecología y Obstetricia. Enero 1982. Vol. XIII. 235-242. 